\title{
Invasive Device Related Nosocomial Infections in Adult Intensive Care Unit of an Oncology Hospital: Evaluation of Five Years
}

\section{Onkoloji Hastanesi Erişkin Yoğun Bakım Ünitesinde İnvaziv Araçla İlişsili Hastane Enfeksiyonları: Beş Yıllık Değerlendirme}

\author{
Gülşen İskender ${ }^{1}$, Sabahat Çeken ${ }^{1}$, Mustafa Cihat Oğan $^{1}$, Habip Gedik ${ }^{2}$, Fazilet Duygu ${ }^{1}$, Mustafa Ertek ${ }^{1}$ \\ ${ }^{1}$ Ankara Onkoloji Eğitim Ve Araştırma Hastanesi \\ ${ }^{2}$ Dr.sadi Konuk Eğitim Ve Araştırma Hastanesi
}

\begin{abstract}
ÖZET
GİRIȘ ve AMAÇ: İnvaziv araç ilişkili hastane enfeksiyonları sürveyansının enfeksiyon kontrol önlemlerinin planlanmasında önemli rolü vardır. Bu çalışmada amacımız, 2009-2013 yılları arasında yoğun bakım ünitesinde yatan hastalarda invaziv araç ilişkili hastane enfeksiyonlarının değerlendirmesi ve malignite varlığının mortalite oranları üzerindeki etkisini araştırmaktır.

YÖNTEM ve GEREÇLER: Hastanemiz yoğun bakım ünitesinde hastane enfeksiyonlarına yönelik aktif sürveyans yapılmaktadır. Hastalara ait veriler Ulusal Hastane Enfeksiyonları Sürveyansı Ağı kayıtlarından alınmıştır. Mikroorganizma tanımlaması klasik yöntemlerle yapılmış, VITEK 2 otomatize sistem ile teyit edilmiştir. Hastane enfeksiyonu tanısı "Centers for Diseases Control and Prevention" kriterlerine göre konulmuştur.

BULGULAR: Yoğun bakım ünitesinde hastane enfeksiyonu insidansı bu dönem içinde ortalama 40,75/1000 hasta günü olup, \%85-100'ünü invaziv araç ilișkili hastane enfeksiyonları olușturmuștur. Santral venöz kateter kullanım oranı ile santral venöz kateter ilişkili kan dolaşımı enfeksiyonu hızlarında beş yılda anlamlı azalma saptanmıştır $(p=0,0005)$. Santral venöz kateter ilişkili kan dolaşımı enfeksiyonları ve ventilatör ilişkili pnömonilerde Gram negatif basiller daha fazla izole edilmiş ve özellikte Acinetobacter spp' nin önemli sorun teşkil ettiği gözlemlenmiștir. Kateter ilişkili üriner sistem enfeksiyonlarında Gram negatif basiller ve kandidalar en çok izole edilen mikroorganizmalar olmuştur. İnvaziv araç ilişkili hastane enfeksiyonu gelişen maligniteli hastalarda yoğun bakım mortalite oranı 2013 yılında, diğer hastalara göre anlamlı olarak daha yüksek bulunmuştur $(\mathrm{p}=0,010)$.

TARTIȘMA ve SONUÇ: Hastanemizde santral venöz kateter ilişkili kan dolaşımı enfeksiyonu hızlarında bir miktar gerileme varken diğer invaziv araç ilişkili enfeksiyonların yüksek seyrettiği gözlemlenmiştir. Yoğun bakım ünitemizde Acinetobacter spp enfeksiyonlarının ciddi bir problem oluşturduğu ortaya çıkmıştır. Ayrıca invaziv araç ilişkili hastane enfeksiyonu olan hastalarda malignite varlığının yoğun bakım mortalite oranlarını artırdığı gözlemlenmiştir.
\end{abstract}

Anahtar Kelimeler: İnvaziv araç, hastane enfeksiyonları, yoğun bakım ünitesi, mortalite, malignite

ABSTRACT
INTRODUCTION: Surveillance of invasive device related nosocomial infections is important for planning infection control procedures. We aimed to evaluate these infections in intensive care unit patients during the period between 2009 and 2013 and the effect of malignancy on mortality rates in this group.

METHODS: Surveillance of nosocomial infections is done prospectively in our intensive care unit. The data of patients were recorded from our national surveillance system. The causative microorganisms of nosocomial infections were classified by conventional methods and verified by VITEK 2 automated system. "Centers for Diseases Control and Prevention" criteria were used to diagnose nosocomial infections.

RESULTS: Mean nosocomial infection incidence in this period was 40,75/1000 patient days and $85-100 \%$ of them were invasive device related nosocomial infections. We found that the usage of central venous catheter and catheter related bloodstream infection rates were declined significantly during this period (p: 0,0005). Gram negative bacilli, especially Acinetobacter spp were the most common microorganisms that caused catheter related blood stream infections and ventilator associated pneumoniae. Gram negative bacilli and Candida spp. were the most common microorganisms causing catheter related urinary tract infections. Intensive care unit mortality rates were statistically higher in patients with malignancy than the others in 2013 (p:0,010).

DISCUSSION AND CONCLUSION: We observed that catheter related blood stream infection rates were decreased during the study period while catheter related urinary tract infections and ventilator associated pneumoniae rates did not change during the study period. Acinetobacter baumannii is a serious problem in our intensive care unit. We observed that intensive care unit mortality rate is higher in patients with invasive device related nosocomial infections in the presence of malignancy.

Keywords: Invasive device, nosocomial infections, intensive care unit, mortality, malignancy 


\section{Giriş}

İnvaziv araç ilişkili hastane enfeksiyonları, santral/periferik venöz kateter, üriner sistem kateteri ve mekanik ventilasyon gibi invaziv uygulamalardan 48 saat sonra başlayan enfeksiyonlardır (1).İnvaziv araç ilişkili hastane enfeksiyonları (İAİHE), yoğun bakım ünitelerinde (YBÜ) morbidite ve mortalitenin en önemli nedenlerindendir (2). Malignite gibi altta yatan ağır hastalıklar, geniş spektrumlu antibiyotik kullanımı ve invaziv girişimler YBÜ'lerindeki enfeksiyon oranlarını artırmaktadır. Enfeksiyon kontrol tedbirleri ile bu enfeksiyonların önemli bir kısmı önlenebilir. YBÜ'lerinde İAİHE aktif sürveyans1 yapılmasıyla aynı hastanede ve hastaneler arasinda, hastane enfeksiyonlarının karşılaştırması ve uygun kontrol önlemlerinin planlanması mümkün olabilmektedir. Centers for Diseases Control and Prevention (CDC) ve National Nosocomial Infection Surveillance (NNIS) tarafindan önerilen formüllere göre hesaplanmış hastane enfeksiyonu insidans dansitesi (HEID) ve İAİHE hıları, benzer kurumlar arasında karşılaştırma yapmada iyi bir ölçüt oluşturmaktadır $\quad(3,4)$. Sağlık Bakanlığı Ulusal Hastane Enfeksiyonları Sürveyans Ağı (UHESA) birimi tarafından açılanan yıllık sürveyans raporları da ülkemizdeki hastanelerin raporlarını gözlemleme ve kıyaslama imkanı sağlamıştır. $\mathrm{Bu}$ çalışmada hastanemiz yoğun bakım ünitesinde 2009 - 2013 y1llarında saptanan invaziv araç ilişkili hastane enfeksiyonları ve malignite varlığının mortalite oranları üzerindeki etkisi retrospektif olarak irdelenmiştir.

\section{Yöntem ve Gereçler}

Hastanemiz Anestezi ve Reanimasyon YBÜ'sinde yatan hastalarda 2009-2013 yıllarında gelişen İAİHE' ları hastaya ve laboratuvara dayalı aktif sürveyans yöntemi ile enfeksiyon kontrol hemşireleri ve enfeksiyon kontrol hekimi tarafindan izlenmiş ve kaydedilmiştir.Hastane enfeksiyonu tanıları CDC tanım kriterlerine göre konulmuştur. Yatan hasta sayısı, yatış günü, mekanik ventilatör (MV) günü, üriner kateter (ÜK) günü ve santral venöz kateter (SVK) günü, gelişen enfeksiyon sayısı ve tipi ile ilgili veriler hesaplanmıştır.
Hastane enfeksiyonu insidans1: HE say1s1 / hasta yatış günü $x 1000$

İnvaziv araç kullanım oranları: invaziv araç kullanım günü / hasta yatış günü

İnvaziv araç ilișkili hastane enfeksiyonu hızları: yıllık araç ilişkili HE sayısı / invaziv araç kullanım günü x 1000

Hastane enfeksiyonu etkeni olarak izole edilen mikroorganizmalar

Mikrobiyoloji

Laboratuvarı'nda tanımlanmıştır.Etkenlerin tanımlanması için konvansiyonel yöntemlerin yanı sira VITEK 2 (Biomerieux, France) tam otomatize bakteri tanımlama sistemi kullanılmıştır. Hastaların tanısı (malignite tanis1 olan ve olmayan) ve tedavi sonucu (yoğun bakımdan taburcu veya yoğun bakımda ölüm) yoğun bakım ünitesi kayıtlarından alınmıştır.

Aralık 2012'den itibaren yoğun bakım ünitesinde invaziv araç bakımında "bundle" sistemi uygulaması başlatılmıştır. $\mathrm{Bu}$ uygulamaya göre intravenöz kateterlerde, aseptik şartlara uyulması, temas öncesi el hijyeni, pansumanın aseptik kurallara uygunluğu, intravenöz tedavilerin aseptik kurallara uygun olarak yapılması ve her gün kateterin gerekliliği kontrol edilmiştir. Mekanik ventilatör uygulanan hastalarda ise "bundle" uygulamasında ağız bakımı, yatak başının 30-45 derece yüksek olması, peptik ülser ve derin ven tromboz profilaksisi, aspirasyonun uygun ve aseptik yapilmas1, ventilatör devrelerinin temizliği, subglotik tüp uygulanmasının kontrolü ve kaf basıncının monitorizasyonu, üriner kateter bakımı ile ilgili ise uygun torba pozisyonu, kateterin bacağa sabitlenmesi, konumunun uygunluğu, torbanın yere değmemesi ve uygun boşaltılması kontrol edilmiştir.

\section{Istatistiksel Analiz}

Sonuçlar, SPSS 16.0 (Chicago, IL) programına kaydedilmiş, verilerin dağılımına göre parametrik ve non-parametrik testler yapılmıştır. İnvaziv araç ilişskili hastane enfeksiyonu gelişen hastalarda mortalite oranları malignitesi olan ve olmayan hastalar arasında ve yıllara göre kıyaslanmıştır. Hazard ratio mortal olan ve olmayan hastalarda risk faktör (malignite) varlığ1 karşılaştırılarak hesaplanmıştır. 


\section{Bulgular}

Hastanemiz Anestezi ve Reanimasyon YBÜ'si 12 yataklı olup hematolojik/solid organ malignitesi ve malignite dişı tanısı olan hastalar takip edilmektedir. Çalışmanın yapıldığ 1 yıllarda gün içinde her 2 hastaya bir hemşire, gece nöbetleri ve hafta sonlarında ise 3 hastaya bir hemşire bakım vermiştir. $\mathrm{Bu}$ ünitede 2009-2013 yılları arasinda yıllık ortalama 3400 hasta günü ile hasta takip edilmiştir.

Hastane enfeksiyonları insidansı YBÜ' sinde 2009 yilında 40,17/1000, 2010 y1lında 42,35/1000, 2011 yilinda 43,42/1000, 2012 y1linda $37,87 / 1000$ ve 2013 y1linda ise 39,98/1000 hasta günü olarak hesaplanmıştır. Beş y1llık ortalama hastane enfeksiyonu insidans1 40,75/1000 hasta günü olarak bulunmuştur. YBÜ' sinde en sik saptanan enfeksiyonlar kan dolaşımı enfeksiyonları, pnömoni ve üriner sistem enfeksiyonları olmuştur. Hastane enfeksiyonlarının \%85100'ini invaziv araç ilişkili hastane enfeksiyonları oluşturmuştur, İAİHE/HE oranlarının yıllara göre dağılımı tablo 1'de sunulmuştur.

Yoğun bakım ünitesinde invaziv araç kullanım oranları ve İAİHE hızı yıllara göre ve National Healthcare Safety Network (NHSN) ve UHESA persentilleri ile kıyaslamalı olarak tablo 2'de sunulmuştur. Mekanik ventilasyon kullanım oranı ve ventilatör ilişkili pnömoni (VIP) hızları, üriner kateter kullanımı ve kateter ilişkili üriner sistem enfeksiyonu (KİÜSE) hızlarında yıllara göre anlamlı fark saptanmamıştır ( $p>0,05)$. Santral venöz kateter (SVK) kullanım oranı ile santral venöz kateter ilişkili kan dolaşımı enfeksiyonu (SVKİ-KDE) hızlarında beş yılda anlamlı azalma saptanmıştır ( $\mathrm{p}=0,0005)$.

İzole edilen mikroorganizmalar incelendiğinde; invaziv araç ilişkili hastane enfeksiyonlarında beş yılda Gram negatif bakteriler $\% 75$ oranlarla Gram pozitiflere $(\% 15,3)$ üstünlük göstermiş olup, kandidalar ise $\% 9,4$ oranında izole edilmiştir. İAİHE'larından izole edilen mikroorganizmalar tablo3-5'te gösterilmiştir. İnvaziv araç ilişkili hastane enfeksiyonu gelişen malignite tanısı olan ve malignite tanıs1 olmayan hastaların sayıs1 tablo 6'da verilmiştir.

Yoğun bakım ünitesinde İAİHE gelişen hastalarda yoğun bakım mortalite oranlarının beş y1llık seyri Grafik 1'de görülmektedir. Malignite tanıs1 olan hastalarda yoğun bakımda mortalite gelişimi, malignite tanısı olmayan hastalara göre 2012 yılı dışında daha yüksek olup, 2013 y1lında bu oran istatistiksel olarak da anlaml 1 bulunmuştur ( p: 0,010, hazard ratio: 3,63 \%95 confidence interval: 1,4-9,44).

Yoğun bakım ünitemizde invaziv araç bakımında "bundle" sistemine uyum değerlendirildiğinde, $2012 \quad$ y1lında uygulamaya uyum $\% 90$, sonraki y1llarda ise SVK bakımında uyum \%100, mekanik ventilasyonda kaf basincinın monitorizasyonu yapılamadığından uyum $\% 90$, üriner kateter bakımında ise zaman zaman idrar torbasının uygun şekilde boşaltılmadığı ve uyumun $\% 80$ 'e düştüğü tespit edilmiştir.

\section{Tartışma}

Yoğun bakım hastaları, altta yatan ciddi hastalıkları olan, konak savunma mekanizmaları bozulmuş, invaziv girişimlerin sık olarak uygulandığ 1 hastalardır. Bu nedenle diğer hastane birimlerine göre bu ünitelerde enfeksiyonlar 5-10 kat daha fazla görülmekte ve daha ciddi sonuçlara yol açabilmektedirler (5). Bizim çalışmamızda HE insidansı 20092013 arasinda ortalama 40,75/1000 hasta günü olup, bu enfeksiyonların \%85-100'ünü İAİHE'ları oluşturmuştur. Ülkemizdeki YBÜ'lerinde yapılan çalışmalarda HE hızları $\% 5.3$ ile \%56.1 arasında değişmektedir (5-9). Hastanemizin, YBÜ'sinde yatan hastaları genellikle komplike onkolojik cerrahi girişimler yapılmış, kemoterapi / radyoterapi almış veya almakta olan, hematolojik maligniteli hastalar veya kök hücre transplantasyonu yapılmış hastalar oluşturmaktadır. Dolayısıyla hastaların çoğunun immün sisteminin baskılanmış olması, invaziv araç ve geniş spektrumlu antibiyotik kullanımının sık ve süresinin uzun olması, yoğun iş yükü nedeniyle enfeksiyon kontrol önlemlerine uyumun azalması, bu yüksek enfeksiyon oranlarını açıklayabilir.

Ülkemizde yayınlanan bazı çalışmalarda ve EPIC II çalışmasında, YBU'lerinde en sık görülen HE türleri pnömoni, bakteremi ve ÜSE olarak sıralanmaktadır. $(1,10,11)$. Hastanemiz YBÜ'sinde İAİHE'larına bakıldığında 2009 ve 2010 yıllarında siklık açısında sırayla SVKİ-KDE > Kİ-ÜSE > VIPP gelmekteyken, 2011-2013 yıllarında bu 
siralama VİP > Kİ-ÜSE > SVKİ-KDE şeklinde değişmiştir (Tablo 1). Bu sıralama farklı merkezlerde değişiklik göstermektedir. $\mathrm{Bu}$ durum, her hastanenin sürveyans verilerine dayanarak kendi enfeksiyon kontrol politikasını geliştirmek ve önceliklerini belirlemek zorunda olduğunun bir kanıtıdır $(12,13)$.Merkezimiz yoğun bakım ünitesinde Aralık 2012'den itibaren invaziv araç bakımında "bundle" sistemi uygulaması başlatılmıştır. Verilerimize bakıldığında bu uygulama ile birlikte SVK kullanım oranı ve SVKİ-KDE hızında başarılı bir düşüş sağlanmışken üriner kateter ve ventilatör kullanım oranları ve enfeksiyon hızlarında aynı başarı elde edilememiştir (Tablo 2). Bunun nedenleri; yoğun iş yükü ve bazen malzeme eksikliği (örn; mekanik ventilasyonda kaf basincinın monitorizasyonunun yapilamaması) nedeniyle "bundle" uygulamasının özellikle gece ve hafta sonu nöbetlerinde bakım veren hemşireler tarafindan tam yerine getirilememesi, yoğun bakım ünitemizde yatan hastaların çoğunlukla komplike malignite tanılı olmaları ve uzun süre yoğun bakım yatışı nedeniyle hastane enfeksiyonu etkeni olan dirençli mikroorganizmalar ile kolonizasyonu ve ileri evre malignite tanıs1 olan hastaların palyatif bakım servisinde yatak sayısının kisitlı olmasından dolayı Anestezi ve Reanimasyon YBÜ'sine endikasyon dışı yatırılması sayılabilir.

Yoğun bakım ünitelerinde birçok çalışmada İAIHHE'larında Gram negatif mikroorganizmaların daha baskın olduğu bildirilmiştir. $(13,14)$. Bizim çalışmamızda da YBU'sinde 5 yilda elde edilen tüm İAİHE etkenlerinde Gram negatifler Gram pozitiflere üstünlük göstermiştir.

Enfeksiyon etkenlerinin spesifik bölgelere göre dağılımına bakıldığında; beş yıllık sürede SVKİ-KDE'larında Gram negatif mikroorganizmalar Gram pozitif mikroorganizmalardan daha fazla izole edilmiş ve özellikte Acinetobacter spp.'nin önemli sorun teşkil ettiği gözlemlenmiştir. Halbuki ülkemizde yapılan pek çok çalışmada Gram pozitif koklarm bu enfeksiyon türünde daha sık görüldüğü bildirilmiştir $(15,16)$

Kateter ilişkili üriner sistem enfeksiyonlarında; Gram negatif mikroorganizmalar ve kandidalar en çok izole edilen mikroorganizmalar olmuştur. Benzer şekilde ÜSE ataklarında Gram negatif basiller ve kandida türlerinin baskın olduğunu bildiren bir çok çalışma vardır $(7,13,16,17)$. VIP'de Gram negatif mikroorganizmalar çoğunlukla izole edilmiş ve 2009'dan başlayan beş y1llık periyotta $A$. baumanii etken olarak ilk sirada yer almıştır. Acinetobacter türlerinin sıklığ hastanemizde olduğu gibi ülkemizde ve diğer ülkelerdeki bazı merkezlerde de giderek artış göstermektedir $(5,16,18)$

Yoğun bakım ünitesinde malignite varlığının mortalite üzerindeki etkisinin araştırıldığı çalışmalarda farklı sonuçlara ulaşılmıştır. Bir çalışmada ileri evre ve genel durumu kritik olan maligniteli hastalarda malignite tanısı olmayanlara kıyasla YBÜ'nde mortalite oranı daha yüksek bulunmuştur ve palyatif tedavi aşamasına gelmiş ileri evre maligniteli hastalarda yoğun bakım servisine yatışın tartışmalı bir konu olduğu düşünülmüştür (19).

Bir cerrahi YBÜ'nde yapılan diğer bir çalışmada ise malignite varlığ 12 ay să̆ kalımı etkilemediği, ileri yaş, taburculukta SAPS (simplified acute physiology score) indeksin yüksekliği ve uzun süre YB yatış1, sağ kalımı etkileyen faktörler olarak bildirilmiştir (20). Tayland'da yapılan bir araştırmada YBÜ'ne yatırılan hematolojik maligniteli hastalarda tedavi sonucu ve erken mortalite risk faktörleri değerlendirilmiş, mortalite oran1 \%55,2 bulunup, nötropeni, mekanik ventilasyon, vazopresör kullanımı, kreatinin yüksekliği ve APACHE II (Acute Physiology And Chronic Health Evaluation II) skorunun yüksek olması mortaliteyi etkileyen önemli risk faktörleri olarak belirlenmiştir (21). Brezilya'da 28 YBÜ'sinde mekanik ventilasyon (invaziv veya non invaziv) ihtiyacı olan yetişkin kanser hastalarında yapılan bir prospektif kohort çalışmasında mortaliteyi etkileyen faktörler ve tedavi sonuçları değerlendirilmiştir. İnvaziv mekanik ventilasyon uygulanan hastalarda mortalite oranı yüksek (\%73) bulunmuş ve ileri evre malignitenin, sonucu kötü etkilediği bildirilmiştir. Merkezimiz YBÜ'sinde genelde malignite tanısı olan hastalarımızda mortalite oran1 malignite tanis1 olmayan hastalara kıyasla daha yüksek olup, 2013 yılında bu fark istatistik olarak da anlamlı bulunmuştur. 
Tablo 1: Yoğun bakım ünitesinde yıllara göre İnvaziv Araç İlişkili Hastane Enfeksiyonu / Hastane Enfeksiyonu oranlar1

\begin{tabular}{|l|l|l|l|l|l|}
\hline HE tipi & $\begin{array}{l}2009 \\
\text { İAं̈E/HE (\%) }\end{array}$ & $\begin{array}{l}2010 \\
\text { İAİHE/HE (\%) }\end{array}$ & $\begin{array}{l}2011 \\
\text { İAİHE/HE (\%) }\end{array}$ & $\begin{array}{l}2012 \\
\text { İAİHE/HE (\%) }\end{array}$ & $\begin{array}{l}2013 \\
\text { İAİHE/HE } \\
(\%)\end{array}$ \\
\hline SVKİ-KDE/KDE & $\begin{array}{l}48 / 52 \\
(92,30)\end{array}$ & $48 / 53(90,56)$ & $35 / 35(100)$ & $30 / 35(85,71)$ & $\begin{array}{l}23 / 27 \\
(85,18)\end{array}$ \\
\hline VİP/Pnömoni & $\begin{array}{l}30 / 31 \\
(96,77)\end{array}$ & $36 / 36(100)$ & $59 / 59(100)$ & $53 / 53(100)$ & $\begin{array}{l}76 / 76 \\
(100)\end{array}$ \\
\hline Kİ-ÜSE /ÜSE & $\begin{array}{l}26 / 26 \\
(100)\end{array}$ & $35 / 35(100)$ & $48 / 48(100)$ & $43 / 43(100)$ & $\begin{array}{l}47 / 48 \\
(97,91)\end{array}$ \\
\hline Diğer & $\begin{array}{l}0 / 4 \\
(0,00)\end{array}$ & $0 / 8(0,00)$ & $0 / 8(0,00)$ & $0 / 3(0,00)$ & $\begin{array}{l}0 / 6 \\
(0,00)\end{array}$ \\
\hline Toplam & $\begin{array}{l}104 / 113 \\
(92,03)\end{array}$ & $\begin{array}{l}119 / 132 \\
(90,15)\end{array}$ & $\begin{array}{l}142 / 150 \\
(94,66)\end{array}$ & $\begin{array}{l}126 / 134 \\
(94,02)\end{array}$ & $\begin{array}{l}146 / 157 \\
(92,99)\end{array}$ \\
\hline
\end{tabular}

HE: Hastane Enfeksiyonu, İAİHE: İnvaziv Araç İlişkili Hastane Enfeksiyonu, SVKİ-KDE: Santral Venöz Kateter İlişkili Kan Dolaşımı Enfeksiyonu, KDE: Kan Dolaşımı Enfeksiyonu, VİP: Ventilatör İlişkili Pnömoni, Kİ-ÜSE: Kateter İlişkili Üriner Sistem Enfeksiyonu, ÜSE: Üriner Sistem Enfeksiyonu

Tablo 2: İnvaziv araç kullanım oranları ve invaziv araç ilişkili hastane enfeksiyonları hızlarının yıllara göre dağılımı. NHSN ve UHESA persentilleri ile kıyaslamalı

\begin{tabular}{|c|c|c|c|c|c|c|}
\hline Yil & $\begin{array}{l}\text { MV kullanım } \\
\text { oranı }\end{array}$ & $\begin{array}{l}\text { VİP } \\
\text { h1z1 }\end{array}$ & $\begin{array}{l}\text { ÜK kullanım } \\
\text { oranı }\end{array}$ & $\begin{array}{l}\text { Kİ-ÜSE } \\
\text { h1z1 }\end{array}$ & $\begin{array}{l}\text { SVK } \\
\text { kullanım } \\
\text { oranı }\end{array}$ & $\begin{array}{l}\text { SVKİ-KDE } \\
\text { hizı }\end{array}$ \\
\hline $\begin{array}{l}2009 \\
\text { NHSN } \\
\text { UHESA }\end{array}$ & $\begin{array}{l}0,61 \\
>90 \\
75-90\end{array}$ & $\begin{array}{l}17,46 \\
>90 \\
50-75\end{array}$ & $\begin{array}{l}0,94 \\
>90 \\
50\end{array}$ & $\begin{array}{l}9,86 \\
>90 \\
>90\end{array}$ & $\begin{array}{l}0,74 \\
>90 \\
50-75\end{array}$ & $\begin{array}{l}\mathbf{2 3 , 0 1} \\
>90 \\
>90\end{array}$ \\
\hline $\begin{array}{l}2010 \\
\text { NHSN } \\
\text { UHESA }\end{array}$ & $\begin{array}{l}0,63 \\
>90 \\
50\end{array}$ & $\begin{array}{l}18,23 \\
>90 \\
75\end{array}$ & $\begin{array}{l}0,95 \\
>90 \\
25\end{array}$ & $\begin{array}{l}11,86 \\
>90 \\
>90\end{array}$ & $\begin{array}{l}0,78 \\
>90 \\
75\end{array}$ & $\begin{array}{l}\mathbf{1 9 , 7 4} \\
>90 \\
>90\end{array}$ \\
\hline $\begin{array}{l}2011 \\
\text { NHSN } \\
\text { UHESA }\end{array}$ & $\begin{array}{l}0,71 \\
>90 \\
75\end{array}$ & $\begin{array}{l}24,10 \\
>90 \\
75\end{array}$ & $\begin{array}{l}0,95 \\
>90 \\
25\end{array}$ & $\begin{array}{l}14,57 \\
>90 \\
>90\end{array}$ & $\begin{array}{l}0,83 \\
>90 \\
75-90\end{array}$ & $\begin{array}{l}\mathbf{1 2 , 1 5} \\
>90 \\
>90\end{array}$ \\
\hline $\begin{array}{l}2012 \\
\text { NHSN } \\
\text { UHESA }\end{array}$ & $\begin{array}{l}0,73 \\
>90 \\
75\end{array}$ & $\begin{array}{l}20,39 \\
>90 \\
75\end{array}$ & $\begin{array}{l}0,95 \\
>90 \\
25\end{array}$ & $\begin{array}{l}12,81 \\
>90 \\
>90\end{array}$ & $\begin{array}{l}0,74 \\
>90 \\
75\end{array}$ & $\begin{array}{l}\mathbf{1 1 , 5 0} \\
>90 \\
75-90\end{array}$ \\
\hline $\begin{array}{l}2013 \\
\text { NHSN } \\
\text { UHESA }\end{array}$ & $\begin{array}{l}0,69 \\
- \\
50-75\end{array}$ & $\begin{array}{l}28,14 \\
- \\
>90\end{array}$ & $\begin{array}{l}0,93 \\
- \\
10-25\end{array}$ & $\begin{array}{l}12,83 \\
- \\
>90\end{array}$ & $\begin{array}{l}0,63 \\
- \\
50\end{array}$ & $\begin{array}{l}9,35 \\
- \\
75\end{array}$ \\
\hline
\end{tabular}

MV: Mekanik Ventilatör, VİP: Ventilatör İlişkili Pnömoni, ÜK: Üriner Kateter, Kİ-ÜSE: Kateter ilişkili Üriner Sistem Enfeksiyonu, SVK: Santral Venöz Kateter, SVKİ-KDE: Santral Venöz Kateter İlişkili Kan Dolaşımı Enfeksiyonu 
Tablo 3: Santral venöz kateter ilişkili kan dolaşımı enfeksiyonlarından izole edilen mikroorganizmaların yıllara göre dağılımı

\begin{tabular}{|c|c|c|c|c|c|}
\hline Mikroorganizma & $\begin{array}{l}2009 \\
\mathrm{~N}(\%)\end{array}$ & $\begin{array}{l}2010 \\
\mathrm{~N}(\%)\end{array}$ & $\begin{array}{l}2011 \\
\mathrm{~N}(\%)\end{array}$ & $\begin{array}{l}2012 \\
\mathrm{~N}(\%)\end{array}$ & $\begin{array}{l}2013 \\
\mathrm{~N}(\%)\end{array}$ \\
\hline Acinetobacter spp & $10(20,83)$ & $12(25)$ & $5(14,29)$ & $7(23,33)$ & $10(43,47)$ \\
\hline Pseudomonas spp & $7(14,58)$ & $4(8,33)$ & $3(8,58)$ & $2(6,67)$ & $0(0,00)$ \\
\hline Ecoli & $8(16,66)$ & $2(4,16)$ & $1(2,85)$ & $2(6,67)$ & $1(4,34)$ \\
\hline Klebsiella spp & $6(12,51)$ & $11(22,91)$ & $3(8,58)$ & $2(6,67)$ & $1(4,34)$ \\
\hline S.aureus & $3(6,25)$ & $0(0,00)$ & $1(2,85)$ & $0(0,00)$ & $1(4,34)$ \\
\hline KNS & $4(8,34)$ & $11(22,91)$ & $14(42)$ & $11(36,66)$ & $6(26,14)$ \\
\hline Enterococcus spp & $4(8,33)$ & $4(8,33)$ & $2(5,71)$ & $2(6,67)$ & $1(4,34)$ \\
\hline Candida spp & $5(10,41)$ & $0(0,00)$ & $1(2,85)$ & $4(13,33)$ & $2(8,69)$ \\
\hline Diğer & $1(2,09)$ & $4(8,33)$ & $5(14,28)$ & $0(0,00)$ & $1(4,34)$ \\
\hline Toplam & $48(100)$ & $48(100)$ & $35(100)$ & $30(100)$ & $23(100)$ \\
\hline
\end{tabular}

KNS: Koagülaz negatif stafilokoklar, Diğer: Seratia spp, viridans sterptokoklar, Proteus spp, Stenotrophomonas spp, Enterobacter spp

Tablo 4: Kateter ilişkili üriner sistem enfeksiyonlarından izole edilen mikroorganizmaların yıllara göre dağılımı

\begin{tabular}{|l|l|l|l|l|l|}
\hline Mikroorganizma & 2009 & 2010 & 2011 & 2012 & 2013 \\
& $\mathrm{~N}(\%)$ & $\mathrm{N}(\%)$ & $\mathrm{N}(\%)$ & $\mathrm{N}(\%)$ & $\mathrm{N}(\%)$ \\
\hline Acinetobacter spp & $2(7,71)$ & $7(20)$ & $7(14,58)$ & $14(32,55)$ & $4(8,51)$ \\
\hline Pseudomonas spp & $8(30,76)$ & $9(25,71)$ & $2(4,16)$ & $2(4,65)$ & $3(6,38)$ \\
\hline Ecoli & $6(23,07)$ & $3(8,57)$ & $12(25)$ & $6(13,95)$ & $7(14,89)$ \\
\hline Klebsiella spp & $1(3,84)$ & $4(11,42)$ & $7(14,58)$ & $2(4,65)$ & $6(12,78)$ \\
\hline Enterococcus spp & $3(11,53)$ & $0(0,00)$ & $5(10,41)$ & $4(9,3)$ & $9(19,15)$ \\
\hline Candida spp & $4(15,38)$ & $10(26,55)$ & $9(18,75)$ & $8(18,62)$ & $16(34,04)$ \\
\hline Diğer & $2(7,71)$ & $3(8,57)$ & $6(12,50)$ & $7(16,28)$ & $2(4,25)$ \\
\hline Toplam & $26(100)$ & $35(100)$ & $48(100)$ & $43(100)$ & $47(100)$ \\
\hline
\end{tabular}

Diğer: Seratia spp,viridans sterptokoklar, Proteus spp, S.aureus, koagülaz negatif stafilokoklar, Stenotrophomonas spp, Enterobacter spp

Tablo 5: Ventilatör ilişkili pnömonilerden izole edilen mikroorganizmaların yıllara göre dağılımı

\begin{tabular}{|l|l|l|l|l|l|}
\hline Mikroorganizma & $\begin{array}{l}2009 \\
\mathrm{~N}(\%)\end{array}$ & $\begin{array}{l}2010 \\
\mathrm{~N}(\%)\end{array}$ & $\begin{array}{l}2011 \\
\mathrm{~N}(\%)\end{array}$ & $\begin{array}{l}2012 \\
\mathrm{~N}(\%)\end{array}$ & $\begin{array}{l}2013 \\
\mathrm{~N}(\%)\end{array}$ \\
\hline Acinetobacter spp & $13(43,34)$ & $17(47,23)$ & $32(53,23)$ & $35(66,03)$ & $39(51,31)$ \\
\hline Pseudomonas spp & $10(33,34)$ & $8(22,22)$ & $10(16,94)$ & $10(18,90)$ & $14(18,42)$ \\
\hline Klebsiella spp & $1(3,33)$ & $6(16,66)$ & $5(8,47)$ & $3(5,66)$ & $11(14,49)$ \\
\hline Candida spp & $1(3,33)$ & $0(0,00)$ & $0(0,00)$ & $0(0,00)$ & $3(3,94)$ \\
\hline Diğer & $5(16,66)$ & $5(13,88)$ & $12(20,33)$ & $5(9,43)$ & $9(11,84)$ \\
\hline Toplam & $30(100)$ & $36(100)$ & $59(100)$ & $53(100)$ & $76(100)$ \\
\hline
\end{tabular}

Diğer: Seratia spp, viridans sterptokoklar, Proteus spp, S.aureus, Koagülaz negatif stafilokoklar, Enterococcus spp, Stenotrophomonas spp, Enterobacter spp , Aspergillos spp 
Tablo 6: Yoğun bakım ünitesinde invaziv araç ilişkili hastane enfeksiyonu saptanan maligniteli ve malignitesiz hasta sayıs

\begin{tabular}{|l|l|l|l|}
\hline YIL & $\begin{array}{l}\text { Maligniteli hasta } \\
\text { say1s1 }\end{array}$ & $\begin{array}{l}\text { Malignitesiz hasta } \\
\text { sayis1 }\end{array}$ & Toplam hasta sayıs1 \\
\hline 2009 & $26(\% 52)$ & 24 & 50 \\
\hline 2010 & $15(\% 33)$ & 30 & 45 \\
\hline 2011 & $39(58)$ & 28 & 67 \\
\hline 2012 & $40(58,8)$ & 28 & 68 \\
\hline 2013 & $49(\% 55)$ & 40 & 89 \\
\hline
\end{tabular}

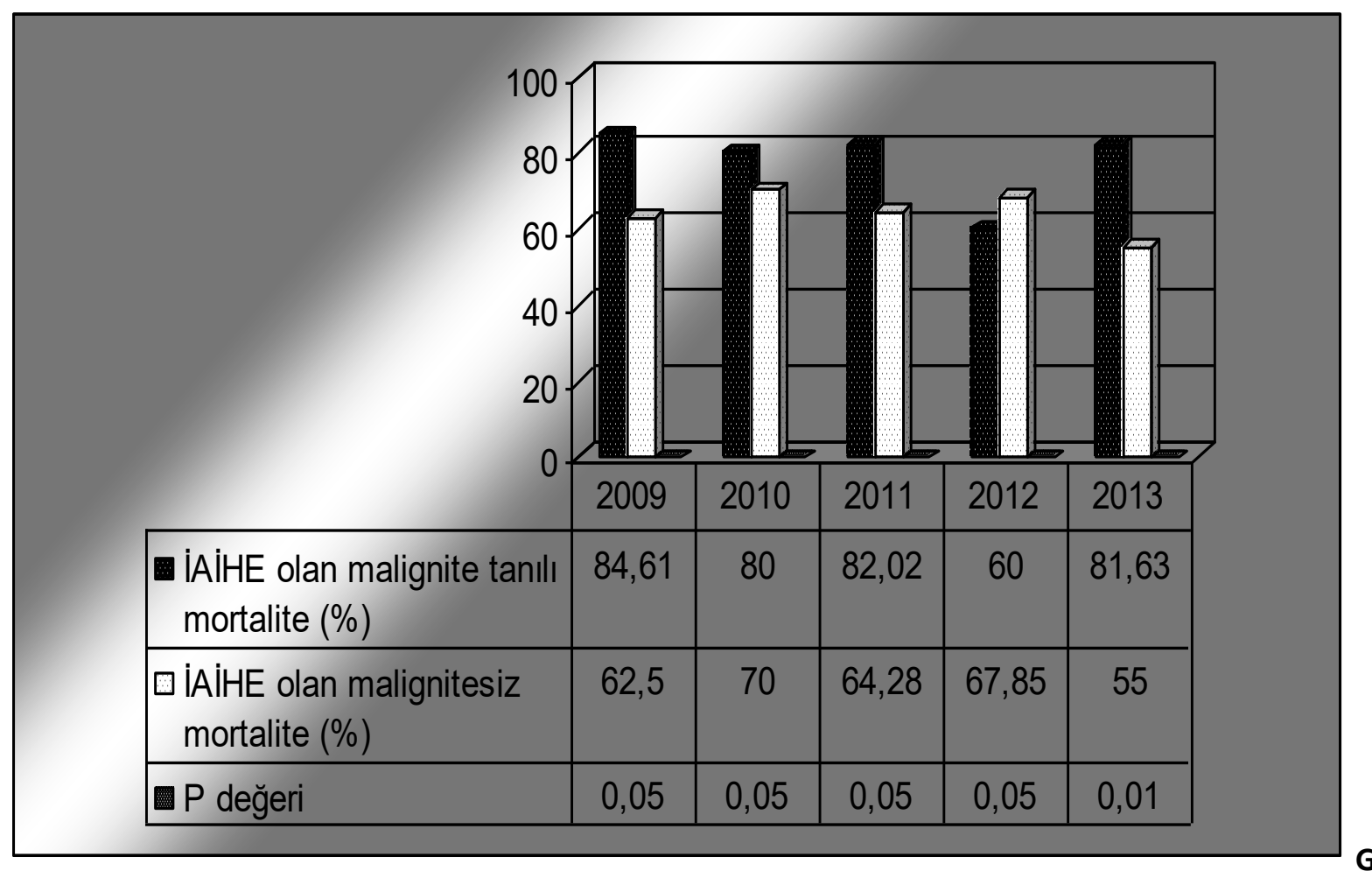

rafik 1: Yoğun bakım ünitesinde invaziv araç ilişkili hastane enfeksiyonu saptanan malignite tanılı ve malignitesiz hastalarda yıllar içinde mortalite oranları

IAiHE: İnvaziv Araç Illişkili Hastane Enfeksiyonu

\section{Sonuç}

Hastanemizde SVKİ-KDE hızlarında bir miktar gerileme varken VİP ve Kİ-ÜSE hızlarının yüksek seyrettiği gözlemlenmiştir ayrıca hastanemiz YBÜ'sinde Acinetobacter spp enfeksiyonlarını ciddi bir problem oluşturduğu ortaya çıkmıştır. Mekanik ventilatör ve üriner kateter bakımında "bundle" uygulamasına dikkatlice uyulması ve bu konuda uzmanların ve yoğun bakım personelinin sürekli eğitim ve denetimi gerektiğini düşünmekteyiz. Elde ettiğimiz sonuçlara göre invaziv araç ilişkili hastane enfeksiyonu olan yoğun bakım hastalarında, malignite varlığı sağkalımı etkilemektedir.

Çıkar çatışması:Çalışmacılar arasında çıkar çatışması yoktur, çalışma için herhangi bir finansal destek alınmamıştır.

Adress for correspondence:Uzm. Dr. Gülşen İskender, Ankara Onkoloji Eğitim Ve Araştrrma Hastanesi. Vatan Cad,demetevler Ankara - Türkiye 


\section{Kaynaklar}

1. Vincent JL, Rello J, Marshall J, et al. International study of the prevelance and out comes of infection in intensive care units. JAMA, 2009; 302: 2323-9

2. Gaynes R, Richards C, Edwards J, et al. Feeding back surveillance data to prevent hospital-acquired infection. Emerging infect Dis. 2001;7: 295-8

3. Dudeck MA, Horan TC, Peterson KD, et al. National Healthcare Safety Network (NHSN) report, data summary for 2011, Device-associated module.AJIC. 2013; 41: 286-300

4. Dudeck MA, Weiner LM, Bridson KA, et al..National Healthcare Safety Network (NHSN) report, data summary for 2012, Device-associated module. AJIC. 2013; 41: 1148-1166

5. Dizbay M, Baş S, Gürsoy A, ve ark. Invasive devicerelated infection surveillance in intensive care units of Gazi University Hospital in 2006-2007. Türkiye Klinikleri J Med Sci. 2009; 29: 140-5

6. Akalın H. Infections in intensive care units: risk factors and epidemiology. Turkish Journal of Hospital Infections. 2001; 5: 5-16

7. Motor VK, Evirgen O, Yula E, ve ark. Mustafa Kemal Üniversitesi Tip Fakültesi yoğun bakım ünitesinde 2011 yılında sağlık hizmeti ile ilişkili infeksiyonların değerlendirilmesi. Aknem Derg. 2012; 26: 137-42

8. Akın A, Coruh AE, Alp E ve ark. Anestezi yoğun bakım ünitesinde beş y1l içerisinde gelişen nozokomiyal enfeksiyonlarda antibiyotik direncinin değerlendirilmesi. Erciyes T1p Derg online. 2011; 33: $1-6$

9. İnan $\mathrm{D}$, Saba $\mathrm{R}$, Keskin $\mathrm{S}$ ve ark. Akdeniz Üniversitesi Hastanesi Yoğun bakım ünitelerinde hastane infeksiyonları. Yoğun Bakım Dergisi. 2002; 2: $129-35$

10. Goktaş U, Yaman G, Karahocagil MK ve ark. Anestezi yoğun bakım ünitesinde hastane infeksiyonu etkenleri ve direnç profillerinin değerlendirilmesi. J Turk Soc Int Care Med. 2010; 8: 13-7

11. Gurbuz A, Sungurtekin H, Gurbuz $M$ ve ark. Anestezi yoğun bakım ünitesinde görülen hastane infeksiyonları. J Turk Soc Int Care Med. 2010; 8: 612

12. Kaya S, Yılmaz G, Cakır E, et al. Device associated hospital infections in neurology- neurosurgery intensive care unit of technical university faculty of medicine. J.Neurol.Sci.[Turk]. 2010; 27: 377-85

13. AkgülA, Karataş M, Öztürk B. Muğla Sitkı Koçman Üniversitesi Tıp Fakültesi Eğitim Araştırma Hastanesi Erişkin Yoğunbakım Ünitelerinde 5 yıllık İnvaziv Araçla İlişkili Hastane Enfeksiyonları Sürveyans1. Türk Yoğun Bakım Derneği Dergisi. 2014; 12: 13-24

14. Leblebicioğlu H, Rosenthal VD, Arıkan OA, et al. Device-associated hospital-acquired infection rates in Turkish intensive care units. Findings of the International Nosocomial Infection Control Consortium(INICC). J Hosp Infect. 2007; 65: 251-7

15. Ak O, Batırel A, Ozer S, et al. Nosocomial infections and risk factors in the intensive careunit of a teaching and research hospital: A prospective cohort study. Med Sci Monit. 2011; 17: 29-34

16. Oncul A, Koculu S, Elevli K. Bir Devlet Hastanesi'nin yoğun bakım ünitelerinde kazanılan hastane enfeksiyonlarının epidemiyolojisi. Şişli Etfal Hastanesi Tıp Bülteni. 2012; 46: 61-2

17. Geyik MF, Ustun C, Hoşoğlu S ve ark. Dicle Üniversitesi Hastanesinde alet ilişkili hastane infeksiyonlar1. Ankem Derg. 2007; 21: 150-4

18. Garnacho-Montero J, Ortiz-Leyba C, FernándezHinojosa E, et al. Acinetobacter baumannii ventilator associated pneumonia: epidemiological and clinical. ICM. 2005; 31: 649-55

19. Markou N, Demopoulou E, Myrianthefs P. The critically ill patient with cancer - indications for Intensive Care Unit admission and outcomes.J BUON. 2008; 13: 469-78

20. Weiler N, Waldmann J, Bartsch DK, et al. Outcome in patients with long-term treatment in a surgical intensive care unit.Langenbecks Arch Surg. 2012 ; 397: 995-9

21. Khwankeaw J, Bhurayanontachai R. Mortality correlation factors in patients with lymphoma and acute myeloid leukemia admitted into the intensive care unit at a referral center in the south of Thailand. J Med Assoc Thai. 2014 ; 97: 77-83 